07,04

\title{
Формирование дефектной структуры монокристалла кварца на ранних этапах деформирования
}

\author{
() Е.Е. Дамаскинская ${ }^{1}$, В.Л. Гиляров ${ }^{1}$, Ю.Г. Носов ${ }^{1}$, К.М. Подурец ${ }^{2}$, \\ А.А. Калоян ${ }^{2}$, Д.В. Корост ${ }^{3}$, И.А. Пантелеев ${ }^{4}$ \\ ${ }^{1}$ Физико-технический институт им. А.Ф. Иоффре РАН, \\ Санкт-Петербург, Россия \\ ${ }^{2}$ НИЦ „Курчатовский институт“, \\ Москва, Россия \\ ${ }^{3}$ Московский государственный университет им. М.В. Ломоносова, \\ Москва, Россия \\ ${ }^{4}$ Институт механики сплошных сред УрО РАН, \\ Пермь, Россия \\ E-mail: Kat.Dama@mail.ioffe.ru
}

Поступила в Редакцию 23 декабря 2021 г.

В окончательной редакции: 23 декабря 2021 г.

Принята к публикации 27 декабря 2021 г.

\begin{abstract}
Проведено исследование накопления дефектов в синтетическом монокристалле кварца при одноосном сжатии на ранних этапах деформирования. Анализ процесса разрушения проведен с помощью трех независимых неразрушающих методов - акустической эмиссии, рентгеновской компьютерной томографии, топографии с использованием источника синхротронного излучения. Показано, что результаты, полученные с помощью трех методов, согласуются между собой и позволяют обнаружить область наиболее интенсивного дефектообразования в объеме образца и, что особенно важно, сопоставить параметры сигналов акустической эмиссии с параметрами дефектов. Данный результат имеет прикладное значение, поскольку позволит в дальнейшем выделять области развития разрушения и оценивать их размеры in situ только по анализу данных акустической эмиссии в тех случаях, когда применение других методов контроля невозможно.
\end{abstract}

Ключевые слова: акустическая эмиссия, рентгеновская компьютерная томография, рентгеновская дифракционная топография, объем дефектов, монокристалл кварца.

DOI: $10.21883 /$ FTT.2022.04.52185.262

\section{1. Введение}

Процесс формирования и развития дефектной структуры в материале под действием механических напряжений до сих пор остается до конца не изученным. Это связано со сложностью экспериментального наблюдения дефектов в объеме в процессе деформирования без нарушения целостности объекта изучения (образца). Одним из методов, позволяющих контролировать поврежденность материала in situ, является регистрация сигналов акустической эмиссии (AE), сопровождающей появление и развитие субмикро-, микро- и макротрещин [1]. Показано, что в кварце акустическая эмиссия возникает при высоких давлениях, нагреве, сопровождает фазовые превращения [2-5].

К настоящему времени накоплен целый ряд эмпирических соотношений между геометрическими параметрами (длиной, площадью, объемом) источников сигналов акустической эмиссии (AE) и параметрами генерации упругих волн (интенсивность АЕ, энергия и др.). В лабораторных экспериментах по деформированию образцов, как правило, эти соотношения получены либо для одиночной трещины [6-8], либо для ансамбля поверхностных трещин в окрестности концентратора напряжений $[9,10]$.
Однако для общего случая формирования дефектной структуры в объеме материала в отсутствии макроконцентратора напряжений до сих пор нет определенного понимания того, каким образом параметры сигналов АЕ связаны с параметрами источника сигнала - дефекта.

Целью настоящей работы является исследование эволюции дефектов с помощью взаимодополняющих методов - акустической эмиссии (AЕ), компьютерной микротомографии (CT) и рентгеновской дифракционной визуализации (XDI - X-ray Diffraction Imaging или топографии).

\section{2. Материал образцов}

В работе использован синтетический кристалл кварца ориентации Z, выращенный способом гидротермального синтеза во Всесоюзном научно-исследовательском институте синтеза минерального сырья [11]. При такой ориентации широкие боковые грани кристалла являются гранями пинакоида $\{0001\}$. Поверхность этих граней обычно имеет бугорчатое строение. Цилиндрические образцы $(d=10 \mathrm{~mm}, h=20-24 \mathrm{~mm})$ вырезались из кристалла перпендикулярно граням пинакоида, и осью образца является направление $\langle 0001\rangle$, т. е. оптическая 


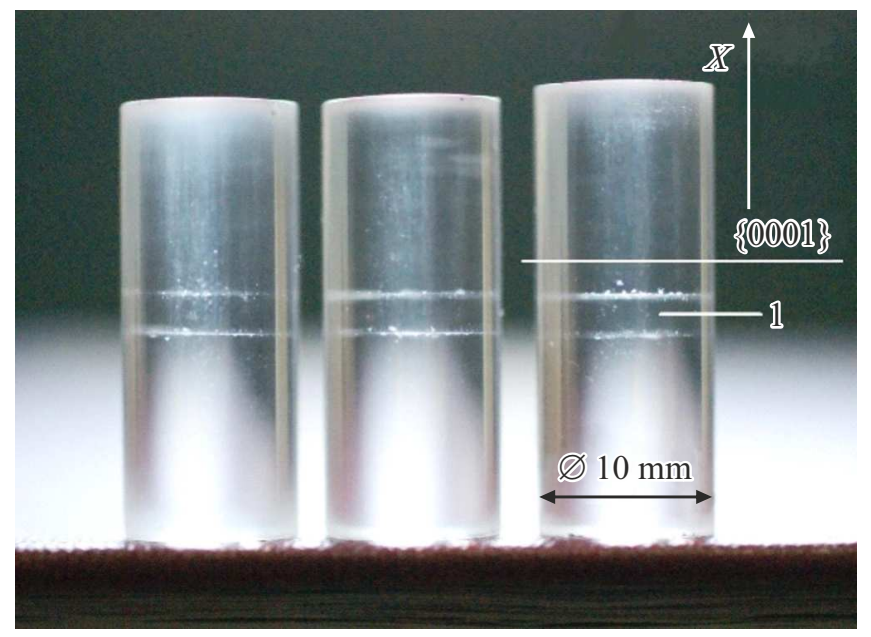

Рис. 1. Образцы монокристалла кварца.

ось. Цилиндрическая поверхность шлифовалась и полировалась до оптической прозрачности. На рис. 1 представлен общий вид образцов для испытаний. Цифрой 1 указана центральная область образца, где находится затравка, поскольку при данном способе выращивания кристалл растет с обеих ее поверхностей. Два ряда пунктирных белых точек на каждом образце (рис. 1) указывают на исходные поверхности затравки, которые декорированы дефектами, образовавшимися в первых слоях нарастающего кварца. Такими дефектами обычно являются газово-жидкие вакуоли размерами от единиц микрон до $0.2-0.3 \mathrm{~mm}$.

Размеры и форма образцов выбирались таким образом, чтобы, с одной стороны, обеспечить возможность определения координат гипоцентров источников акустической эмиссии, а с другой - добиться наилучшего пространственного разрешения при рентгеновской компьютерной томографии.

\section{3. Методика эксперимента}

Образцы подвергались одноосному квазистатическому сжатию со скоростью нагружения (смещения нагружающих плит) $5 \mu \mathrm{m} / \mathrm{min}$ на электромеханической машине AGX-Plus (Shimadzu, Япония, максимальное усилие 30 tons). Механическое напряжение прикладывали параллельно оси цилиндра. Сжатие осуществлялось до усилия, равного $6 \mathrm{kN}$, что соответствует 0.08 от $F_{\max }$ $\left(F_{\max }-\right.$ разрушающая нагрузка, определенная в предварительных экспериментах). Затем образец выдерживался при постоянной деформации до тех пор, пока активность AЕ не спадала до нуля.

В процессе нагружения образца производилась регистрации сигналов акустической эмиссии в реальном времени с помощью системы Amsy-5 Vallen (Германия). Два пьезопреобразователя AE105A (рабочий частотный диапазон 450-1150 kHz) крепились в специальных полых цилиндрических плитах, с помощью которых непосредственно осуществлялось нагружение образца. Данное размещение пьезопреобразователей дало возможность определять координаты гипоцентров сигналов AE c точностью не хуже $1.5 \mathrm{~mm}$. Каждый сигнал акустической эмиссии характеризовался временем излучения, координатой источника по высоте образца и энергией. Детали эксперимента были описаны ранее, например, [12].

Исследование дефектной структуры образцов методом рентгеновской микротомографии (СТ) до и после механических испытаний проводилось с помощью томографа SkyScan 1172 (Bruker, Belgium), оснащенного микрофокусной рентгеновской трубкой Hamamatsu 100/250 и детектором (ПЗС-матрица 11 Mpixel). При сканировании устанавливались следующие параметры: напряжение $70 \mathrm{kV}$, ток $129 \mu \mathrm{A}$, расстояние от источника до камеры (детектора) $213.580 \mathrm{~mm}$, расстояние от источника до объекта $75.030 \mathrm{~mm}$. Шаг поворота образца $0.200^{\circ}$, время экспозиции $3770 \mathrm{~ms}$, продолжительность съемки 24 h. Реконструкция, т. е. пересчет набора полученных проекций в набор плотностных сечений, отображающих внутреннюю структуру образца, производилась с помощью программного обеспечение NRecon, компании SkyScan. Реконструкция всех данных была произведена на одних параметрах яркости по HU (от -650 до 2200), что позволяет производить сопоставление результатов различных съемок, а также обеспечивает объективный контроль результатов.

Выбранный размер образцов позволил добиться пространственного разрешения компьютерной томографии $\sim 3 \mu \mathrm{m}$, что является максимально возможным для образцов данного размера с учетом физических принципов томографии, конструктивных особенностей рентгеновской трубки и камеры томографа [13].

Томографическая съемка образцов, выполненная до механических испытаний, выявила дефекты, которые остались от поверхности затравки. Трехмерная визуализация структуры образца вблизи затравки показана на рис. 2. Видно, что дефекты расположены случайным образом внутри образца в области с координатами

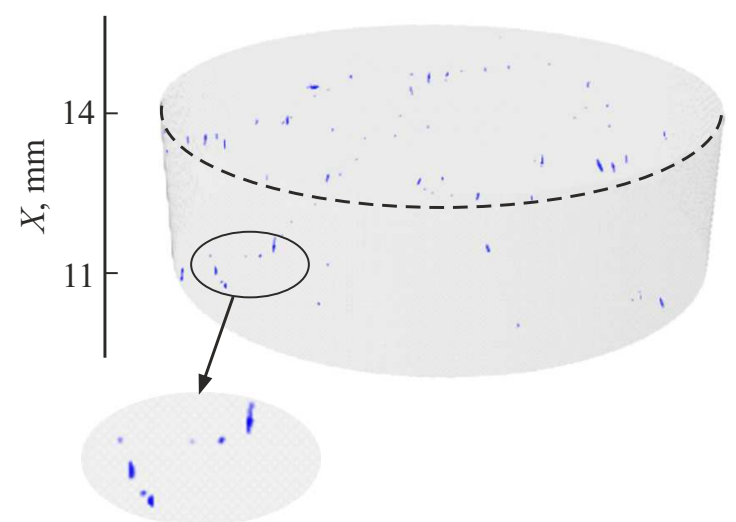

Рис. 2. Трехмерная визуализация исходных дефектов (синие объекты). 
11-14 mm по высоте. Именно в этой области находилась затравка. Вне области затравочной плоскости дефектов типа трещин (несплошностей) не обнаружено.

Томография способна обнаружить только те дефекты, которые характеризуются вариацией электронной плотности материала. К таким дефектам могут относиться пустоты и включения другой фазы. Однако в кристаллах могут существовать дефекты, не влияющие на плотность материала, но создающие внутренние напряжения, что может сказываться на процессе разрушения. Такие поля напряжений создаются дефектами кристаллической структуры и их скоплениями. Рентгеновская топография позволяет получить изображение дальнодействующих полей деформаций в виде изменения интенсивности (за счет экстинкционного контраста) [14].

В работах [15-18] исследовались дефекты структуры кварца с целью выяснения их влияния на функциональные свойства оптических и полупроводниковых приборов.

В настоящей работе предпринята попытка поиска корреляции между наличием дефектов кристаллического строения и разрушением образцов кварца под действием механической нагрузки, т.е. образованием и развитием магистральной трещины.

Топографические исследования проведены на станции „Медиана“ Курчатовского специализированного источника синхротронного излучения „КИСИ-Курчатов““ Изображения (топограммы) записывались с помощью двухкоординатного детектора на основе матрицы CCD размерностью $4008 \times 2672$, сцинциллятора GdOS:Tb, с размером пикселя $8.9 \mu \mathrm{m}$. Обработка изображений проводилась с использованием программы ImageJ [19].

В случае топографии на белом пучке образец кварца устанавливали горизонтально в симметричной геометрии на просвет с горизонтальной плоскостью дифракции, отражение под брэгговским углом $\approx 12^{\circ}$ регистрировали детектором, расположенным на расстоянии $30 \mathrm{~cm}$ от образца. Пучок ограничивали вертикальной щелью шириной $300 \mu \mathrm{m}$, при этом топограмма представляла проекцию объема образца, через который проходит пучок (секционная топограмма).

В случае топографии на монохроматическом пучке использовалась вертикальная плоскость дифракции. В качестве монохроматора для расширения пучка применялся плоский кристалл кремния с плоскостью поверхности, отклоненной от (100) на $7^{\circ}$, отражение (511) (соответственно, угол между поверхностью и отражающей плоскостью $\left.9^{\circ}\right), \lambda=0.56 \AA$. Фактор асимметрии отражения $b=0.1$, расходимость пучка после монохроматора составляет по оценкам $0.2^{\prime \prime}$. Съемка заключалась в получении серии изображений при повороте образца с шагом 0.6". Время сьемки одного изображения составляло $10 \mathrm{~s}$. Образец устанавливали горизонтально, так что детектор мог регистрировать изображение всего кристалла; таким образом, с помощью рентгеновской топографии мы можем наблюдать распределение деформаций по всему объему кристалла. Однако вследствие дисперсии разные участки кристалла отражали неодновременно. В этом случае для получения изображения всего кристалла строится карта распределения пиковых значений интенсивности (на пике кривой дифракционного отражения) по всему массиву топограмм, полученных при различных угловых положениях кристалла [20]. Также массив топограмм может быть использован и для построения карты распределения ширины кривой качания кристалла, являющейся характеристикой его совершенства [21].

\section{4. Результаты и обсуждение}

На рис. 3 приведены временные зависимости деформации и активности $\mathrm{AE}$ (число сигналов в единицу

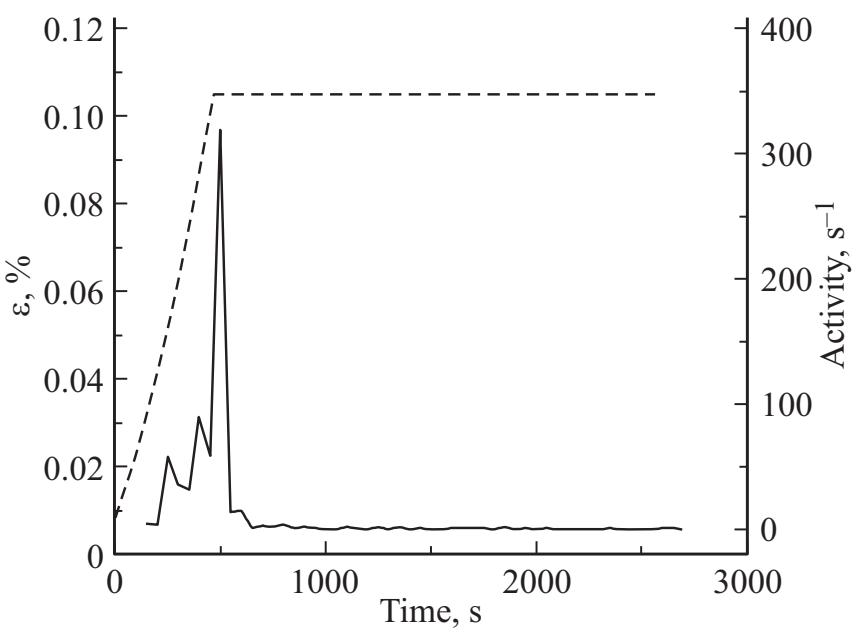

Рис. 3. Изменение деформации (штриховая линия) и активности $\mathrm{AE}$ (сплошная линия) в процессе эксперимента.

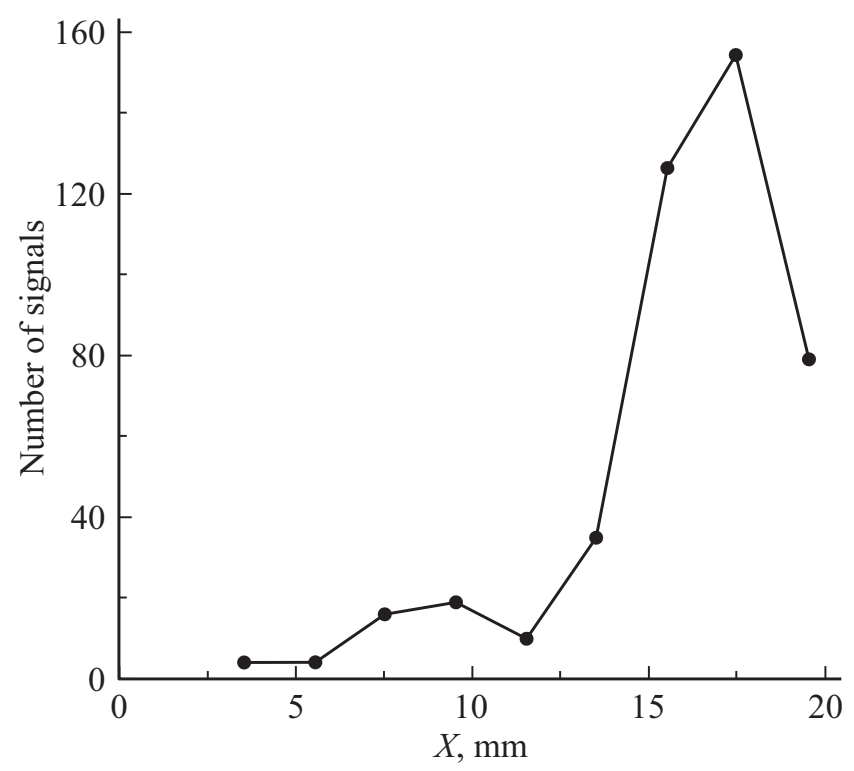

Рис. 4. Распределение сигналов АЕ по координате (по высоте образца). 


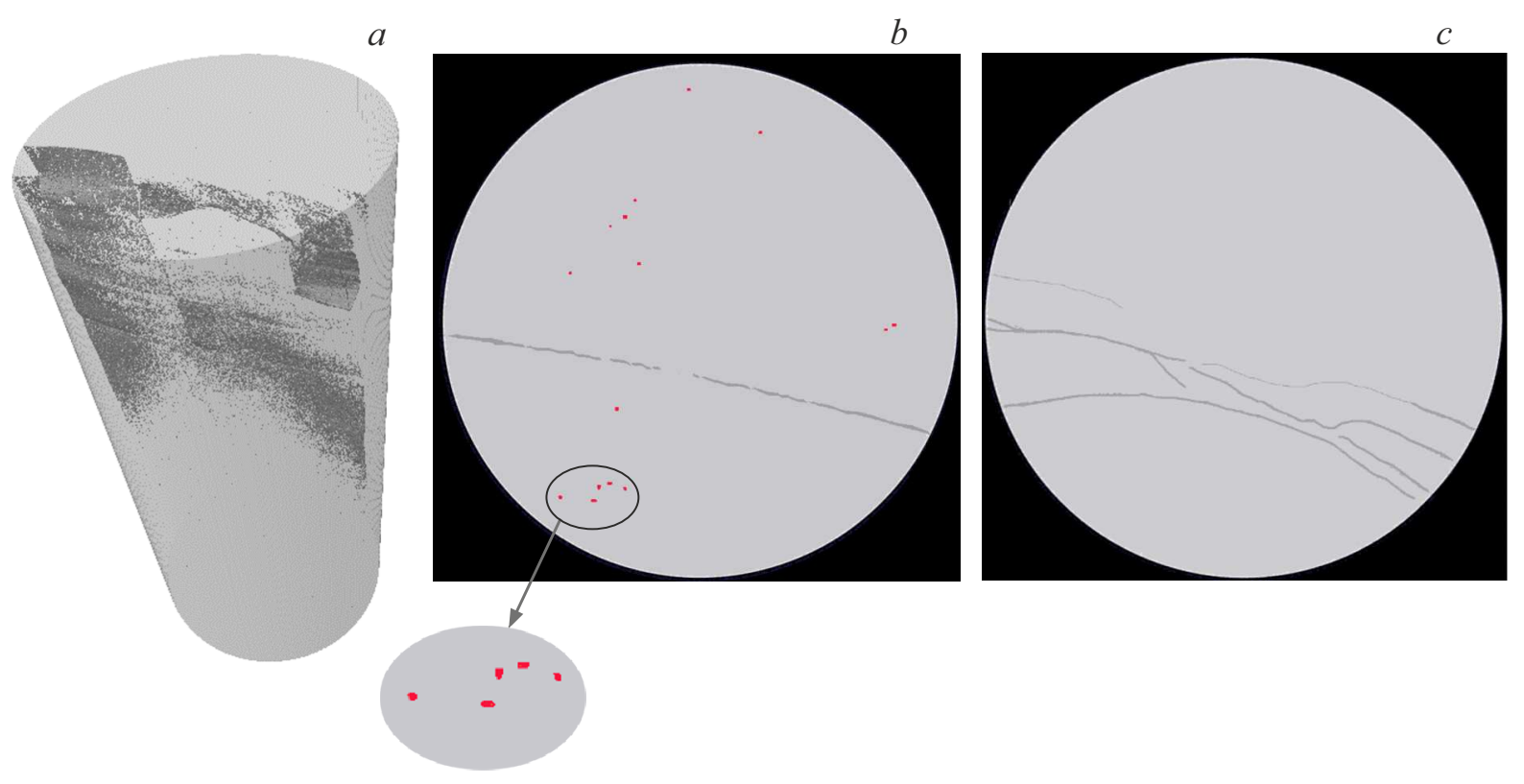

Рис. 5. Трехмерная визуализация дефектной структуры, построенная по данным рентгеновской томографии с использованием специализированного программного обеспечения CTan и CTvol $(a)$, и примеры томографических срезов: $b-$ срез из области вблизи затравки - исходные дефекты показаны красным цветом, трещина - черным; $c$ - срез из области вдали от затравки с наиболее разветвленной трещиной (черные линии).

времени). При расчете активности вся совокупность событий разбивалась на равные по времени интервалы (в данном случае, $50 \mathrm{~s}$ ), затем определялось число событий в каждом интервале. Видно, что в период увеличения деформации активность нарастает. Далее при постоянной деформации активность спадает и сохраняет низкие значения (единицы сигналов).

Распределение гипоцентров сигналов АЕ по высоте образца приведено на рис. 4. Видно, что наибольшее число источников (в 7-10 раз больше, чем в других областях) зарегистрировано в области 16-20 mm. Этот результат позволяет предположить, что именно в этой области происходит наиболее интенсивное дефектообразование.

Согласно данным, описанным ранее в разд. 3, в этой области не присутствуют дефекты, связанные с затравкой. Это позволяет предположить, что исходные дефекты в данном случае не являются концентраторами напряжений и источником образования трещин. Действительно, томографическая съемка образца, подвергнутого нагрузке, подтверждает это предположение. На рис. 5 показана трехмерная визуализация образовавшейся трещины $(a)$ и примеры томографических срезов $(b, c)$, параллельных основанию цилиндра. Видно, что трещина (черная линия на рис. $5, a$ ) образовалась вне исходных дефектов (красные объекты на рис. 5, $b$ ). Сопоставление томографических срезов, полученных до и после нагружения, позволяет говорить о том, что исходные дефекты при данном уровне нагрузки не претерпели никаких изменений, т. е. не наблюдается ни прорастания дефектов, ни их закрытия.
На рис. 6 показано изменение объема дефектов в слоях высотой $2 \mathrm{~mm}$, определенное на основании данных СТ с помощью программного пакета СTan. Также для каждого из слоев была вычислена средняя энергия $\left(E_{\text {mean }}\right)$ сигналов АЕ, гипоцентры которых находятся в данном слое. Наибольший объем дефектов зарегистрирован в области 16-20 mm. Именно в этой области трещина имеет разветвленную структуру, что демонстрируют томографические срезы (рис. 5, c).

Сопоставление распределений объема дефектов и средней энергии АЕ сигналов вдоль образца показы-

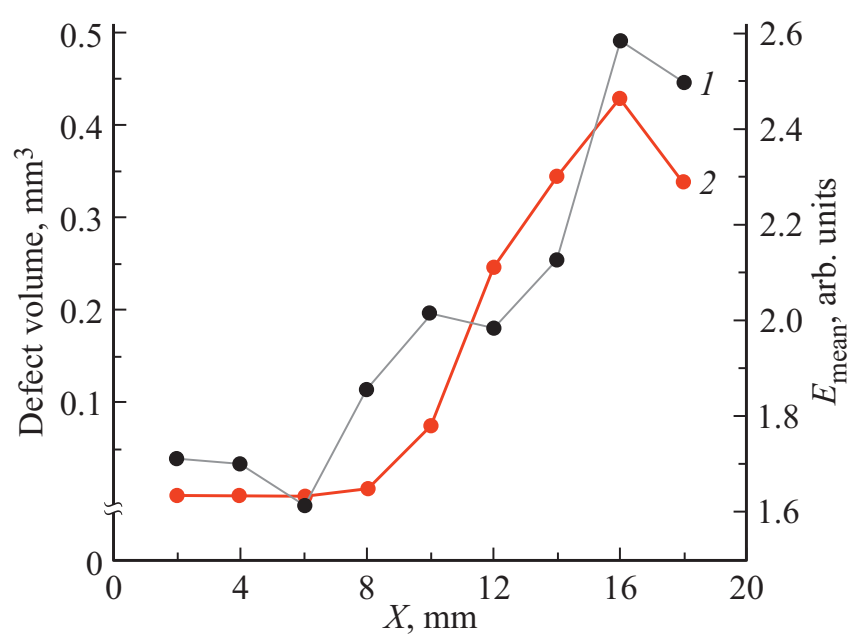

Рис. 6. Изменение средней энергии сигналов АЕ (серая кривая 1) и объема дефектов (красная кривая 2) по координате (высоте образца). 


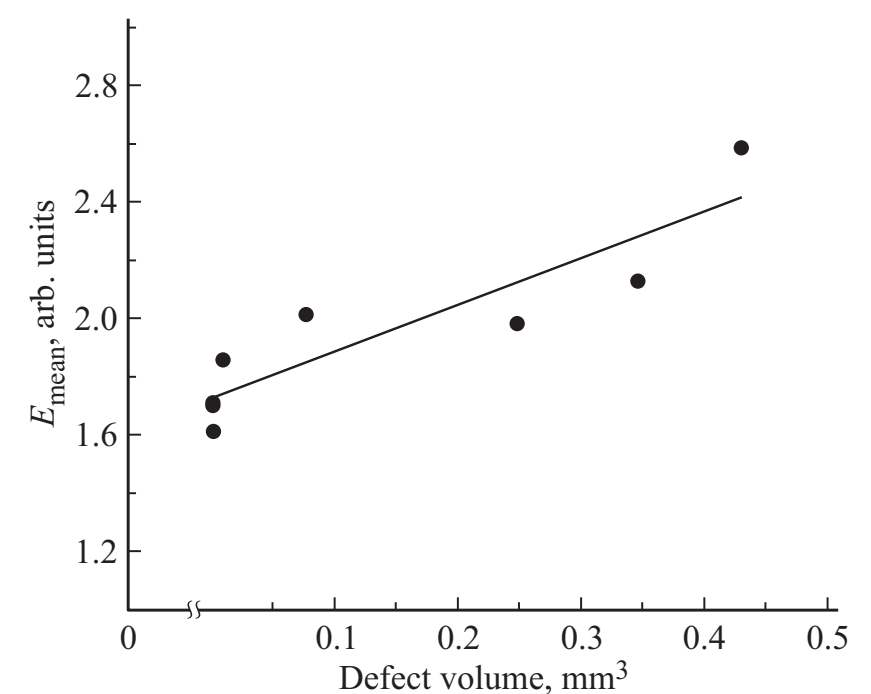

Рис. 7. Зависимость средней энергии сигналов АЕ от объема дефектов.

вает, что увеличение объема дефектов коррелирует с ростом энерговыделения. Подобный результат был получен ранее [22] при исследовании накопления дефектов в природных гетерогенных материалах. Это позволяет говорить об общности результатов и их независимости от конкретного материала.

Кроме того, установлена корреляция между средней энергией сигналов АЕ и объемом дефектов (рис. 7). Зависимость аппроксимируются линейной функцией $\left(R^{2}=0.89\right)$. Данный результат позволяет в дальнейшем оценивать объем образовавшихся дефектов по параметрам сигналов АЕ.

Рентгеновская топография показала, что основным „мотивом“ дефектной структуры является наличие линейных образований в форме волнистых волокон, простирающихся по длине образца, т.е. по направлению роста кристалла (рис. 8,9 ). На секционных топограммах эти образования имеют вид штриха, ширина которого определяется шириной щели. На топограммах в монохроматическом пучке также наблюдается волокнистая структура, причем волокна не являются изображением отдельных линейных дефектов (дислокаций), так как во многих случая наблюдаются их обрывы, что нехарактерно для дислокаций.

Элементарные дефекты, такие как дислокации, малоугловые границы и пр., на топограммах не выявляются. Также наблюдаемые несовершенства не являются несплошностями. На топограммах наблюдается затравочная плоскость; плотность волокон в затравке меньше, чем в остальном объеме кристаллов. Некоторые волокнистые образования существуют только вне затравки, некоторые дают более яркое изображение вне затравки по сравнению с изображением внутри затравки (рис. 10). Можно предположить, что волокнистая структура отражает скопления дефектов, в основном дислокаций, плотность которых постоянна вдоль волокна и значительно меняется в поперечном направлении. В кристалле имеется область, в которой плотность волокнистых образований повышена по сравнению со средней по кристаллу. На топограммах, представленных на рис. 9, $a$ и $b$, данная область указана стрелкой.

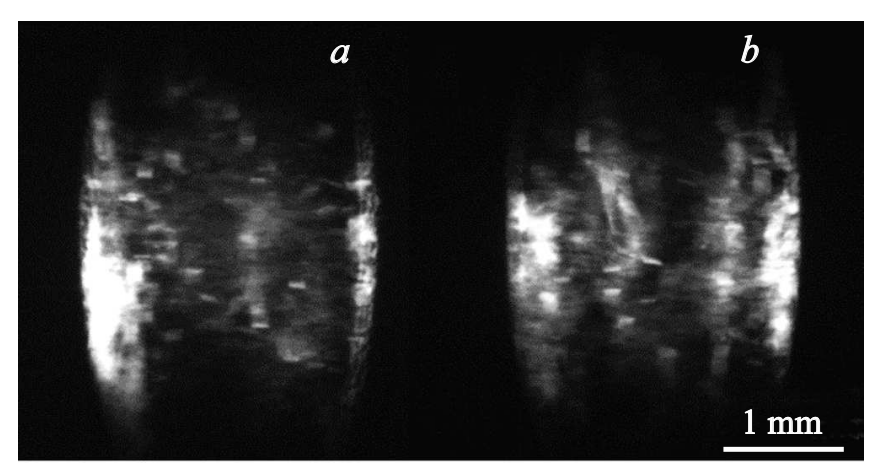

Рис. 8. Две секционные топограммы $(a, b)$ кристалла кварца, полученные со сдвигом кристалла $1 \mathrm{~cm}$.

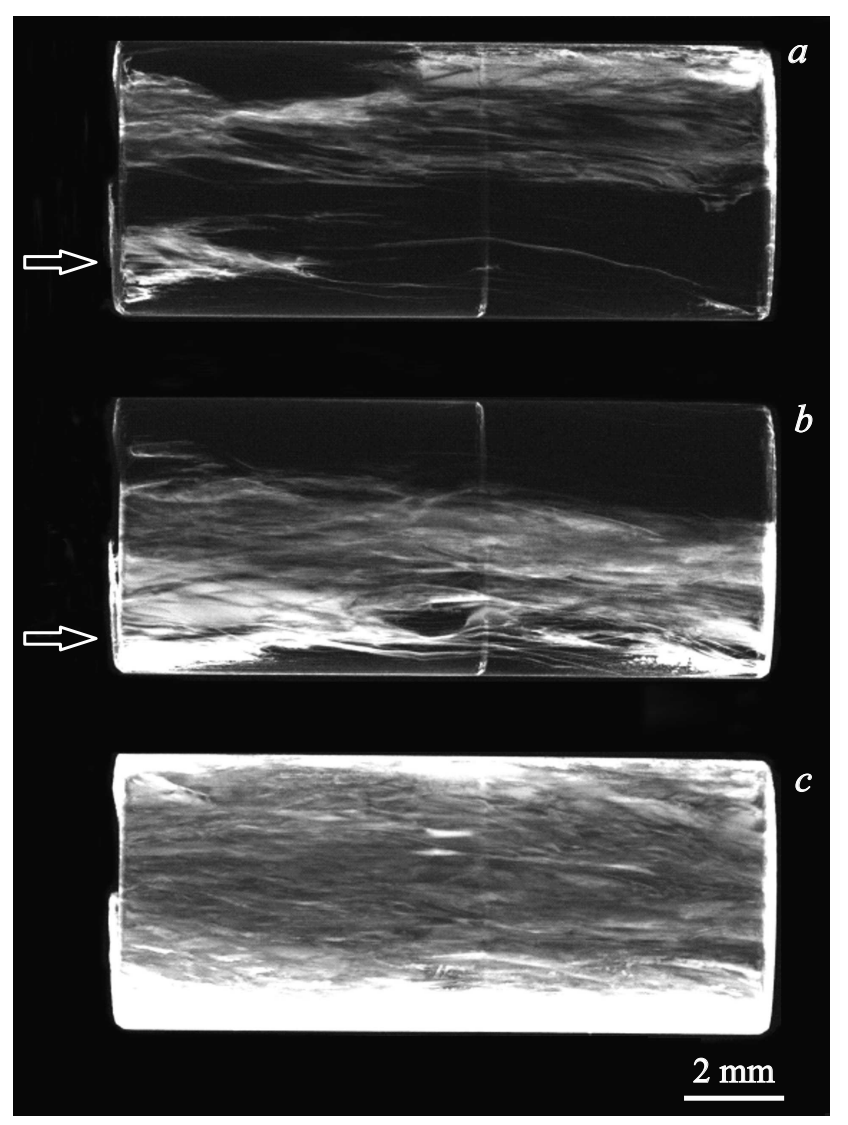

Рис. 9. Две топограммы кристалла кварца, снятые до приложения механической нагрузки $(a, b)$, полученные с угловым интервалом $9.4^{\prime \prime}$, и карта максимальных значений интенсивности $(c)$. Посередине изображения наблюдается граница одновременного отражения. Стрелкой указана область повышенной плотности дефектов. 
Были получены топограммы кристалла кварца после механического воздействия. Анализ данных АЕ и СТ показал, что наиболее развитая трещина (наибольший

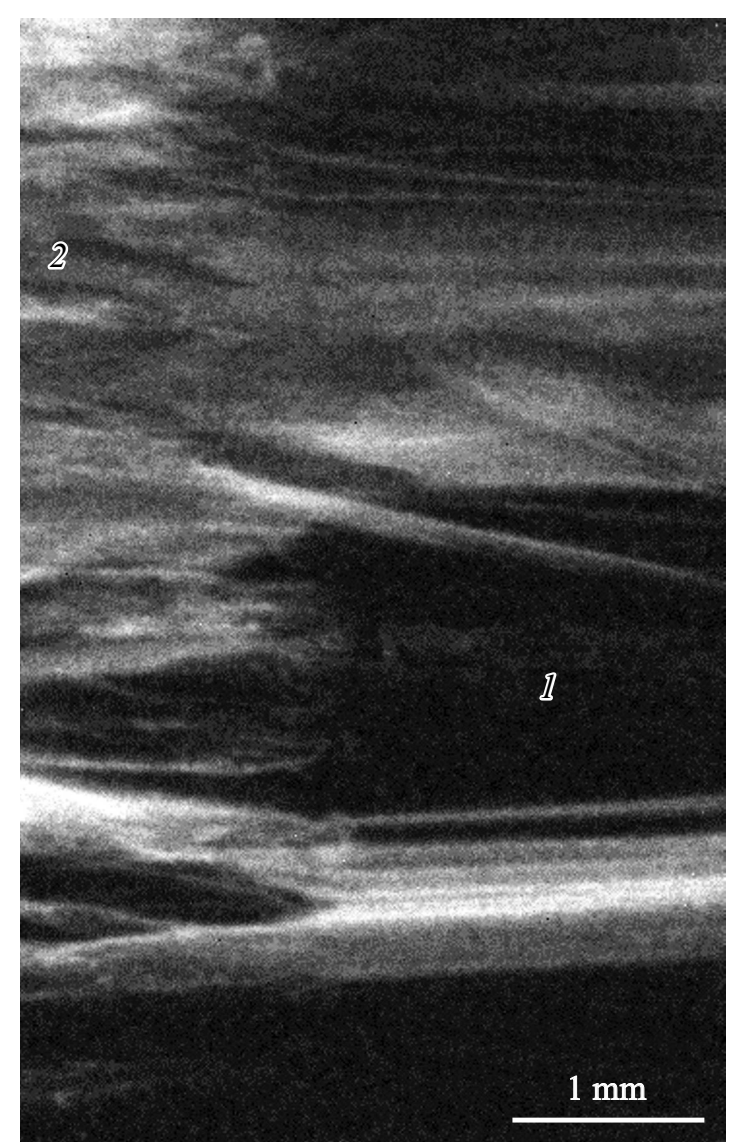

Рис. 10. Топограмма кристалла вблизи границы раздела затравки (1) и основного кристалла (2).

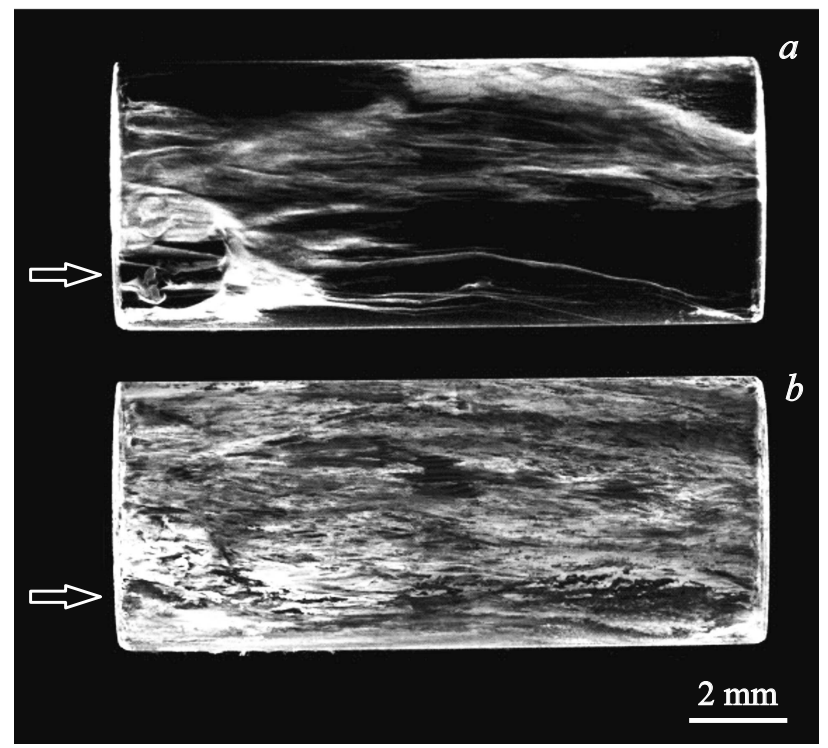

Рис. 11. Топограмма кристалла кварца, снятая после приложения механической нагрузки $(a)$, и карта значений ширины кривой качания $(b)$. Стрелкой указана область разрушения. объем дефектов) образовалась в области с координатами 16-20 mm. И на топограммах (рис. 11) в этой же пространственной области наблюдается повышенная интенсивности.

Также, на полученной из последовательностей топограмм при разных углах, карте ширин кривой качания, в той же области кристалла, наблюдается повышение ширины $\left(15-20^{\prime \prime}\right)$ по сравнению со значением, характерным для неповрежденного кристалла (3-5"). Расположение области разрушения в кристалле соответствует расположению области, обнаруженной на топограммах, снятых до механического воздействия, в которой плотность волокнистых образований была повышена (рис. 9, $a$ и $b$ ).

Таким образом, дифракционная топография позволила обнаружить в исходном образце область повышенных деформаций. Именно в этой области после механических воздействий произошло наиболее интенсивное трещинообразование, о чем свидетельствуют результаты компьютерной томографии.

Следует отметить, что наблюдаемая в наших экспериментах топографическая картина волокон в объеме кристалла совпадает с неоднократно описанной $[11,23]$ картиной структурных дефектов кварца - свилей, вызванных скоплениями ростовых дислокаций. Дислокации могут как прорастать из затравки, так и образовываться на частицах захваченной из раствора примеси. В процессе роста кристалла дислокации собираются в „жгуты“ и „стенки“, порождающие свилевое (волокнистое) строение, т.е. то, что для других кристаллов обозначается термином „блочность“. Значительная разориентация отдельных областей свилеватых (волокнистых) кристаллов позволяет видеть эти блоки на рентгеновских топограммах.

Поскольку затравка вырезается из кристалла с малым количеством дислокаций (или из бездислокационного), то, как мы наблюдали в наших экспериментах, свили (волокна) в затравке отсутствуют или их мало.

Таким образом, наблюдаемое нами образование трещин в кристалле кварца в местах повышенной плотности свилей (волокнистых образований) позволяет сделать вывод, что первичным структурным дефектом, приводящим при нагружении к появлению трещин, являются „жгутообразные“ скопления дислокаций по границам свилей.

\section{5. Заключение}

Проведено исследование накопления дефектов в синтетическом монокристалле кварца при одноосном сжатии на ранних этапах деформирования. Одновременное применение трех независимых неразрушающих методов - акустической эмиссии, рентгеновской компьютерной томографии, топографии с использованием источника синхротронного излучения - позволило получить более полную информацию о развитии разрушения. 
Анализ данных рентгеновской компьютерной томографии показал, что уже при достаточно малых напряжениях начинается формирование магистральной трещины. Установлено, что трещина не затрагивает исходные дефекты. Показана удовлетворительная корреляция объема образовавшихся дефектов и средней энергии сигналов $\mathrm{AE}$, зарегистрированных при их образовании.

Топография, полученная с использованием источника синхротронного излучения, показала, что в образце, не подвергнутом механическому воздействию, выделяется область повышенных деформаций. С помощью рентгеновской компьютерной томографии установлено, что после приложения нагрузки именно в этой области произошло наиболее интенсивное трещинообразование.

Важно отметить, что анализ параметров сигналов АЕ также позволяет выделить эту же пространственную область: именно здесь наблюдается повышенное энерговыделение и активность АЕ.

Таким образом,

- дифракционная топография позволила обнаружить область повышенных внутренних деформаций в исходном кристалле;

- компьютерная томография визуализировала трещины, возникшие после приложения нагрузки, и позволила получить данные о форме, размерах и объеме дефектов;

- анализ параметров сигналов акустической эмиссии позволил выделить пространственную область образца, в которой дефектообразование протекало наиболее интенсивно.

Показано, что результаты, полученные с помощью трех методов, согласуются между собой и позволяют обнаружить область наиболее интенсивного дефектообразования в объеме образца и, что особенно важно, сопоставить параметры сигналов $\mathrm{AE}$ с параметрами дефектов.

Данный результат имеет прикладное(практическое) значение, поскольку позволяет в дальнейшем детектировать области разрушения и оценивать их размеры in situ только по анализу данных акустической эмиссии в тех случаях, когда применение других методов контроля невозможно (например, при эксплуатации промышленных объектов).

\section{Конфликт интересов}

Авторы заявляют, что у них нет конфликта интересов.

\section{Список литературы}

[1] X. Lei, S. Ma. Earthquake Sci. 27, 6, 627 (2014).

[2] A. Schmidt-Mumm. Phys. Chem. Minerals 17, 545 (1991).

[3] P.W.J. Glover, P. Baud, M. Darot, P.G. Meredith, S.A. Boon, M. LeRavalec, S. Zoussi, T. Reuschlé. Int'l J. Geophys. 120, 3, 775 (1995).

[4] J. Gasc, A. Schubnel, F. Brunet, S. Guillon, H.-J. Mueller, C. Lathe. Phys. Earth. Planetary Interiors 189, 3-4, 121 (2011).
[5] V.I. Vettegren, V.S. Kuksenko, P.I. Shcherbakov. Tech. Phys. 56, 4, 577 (2011).

[6] K. Peng, S. Shi, Q. Zou, J. Mou, J. Yu, Y. Zhang, Y. Cheng. Energy Sci. Eng. 8, 9, 3117 (2020).

[7] S.G. Shah, J.M. Chandra Kishen. Eng. Fracture Mech. 87, 1, 36 (2012).

[8] S. Yuyama, Z.-W. Li, M. Yoshizawa, T. Tomokiyo, T. Uomoto. NDT \& E Int'l, 34, 6, 381 (2001).

[9] Y. Seo, Y.R. Kim. KSCE J. Civil Eng. 12, 4, 237 (2008).

[10] J. Zhang. Hindawi. Shock Vibration.2018, Article ID 3057628, (2018).

[11] Синтез минералов / Отв. ред. Б.А. Дороговин. 2-е изд. ВНИИСИМС (2000). Т. 1. 642 с.

[12] Е.Е. Дамаскинская, В.Л. Гиляров, И.А. Пантелеев, Д.Р. Гафурова, Д.И. Фролов. ФТТ 60, 9, 1775 (2018).

[13] T. Toth, R. Hudak. Acta Mech. Slovaca 17, 4, 40 (2013).

[14] I.L. Shul'pina, I.A. Prokhorov. Crystallogr. Rep. 57, 661 (2012).

[15] A.R. Lang. Nature 220, 652 (1968).

[16] Л.И. Цинобер, В.Е. Хаджи, Л.А. Гордиенко, Л.Т. Литвин. В сб.: Рост кристаллов. Наука, М. (1977). Т. 12. С. 75.

[17] V. Lerche, P. Dornfelder, J. Hartwig. Phys. Status Solidi A 128, 2, 269 (1991).

[18] Y. Epelboin, A. Authier. Acta Crystallogr. A 39, 767 (1983).

[19] C.A. Schneider, W.S. Rasband, K.W. Eliceiri. Nature Meth. 9, 7, 671 (2012).

[20] A.A. Kaloyan, K.M. Podurets, I.A. Prokhorov, E.S. Kovalenko, I.Zh. Bezbakh, A.O. Okunev, A.I. Gribenyukov, G.A. Verozubova. Crystal Res. Technol. 53, 11, 1800154 (2018).

[21] D. Lübbert, T. Baumbach, J. Härtwig, E. Boller, E. Pernot. Nucl. Instrum. Meth. Phys. Res. B 160, 4, 521 (2000).

[22] Е.Е. Дамаскинская, И.А. Пантелеев, Д.В. Корост, К.А. Дамаскинский. ФТТ 63, 1, 103 (2021).

[23] Г.В. Клещев, И.В. Кабанович, Л.Н. Черный. Докл. АН CCCP 174, 3, 585 (1967).

Редактор Е.В. Толстякова 